\title{
An Indicator for the Suppression of Fatigue Crack Growth by Hybrid Peening*
}

\author{
Osamu TAKAKUWA**, Kouhei YAMAMIYA** and Hitoshi SOYAMA** \\ ${ }^{* *}$ Department of Nanomechanics, Graduate School of Engineering, Tohoku University. \\ 6-6-01 Aoba, Aramaki, Aoba-ku, Sendai, Miyagi 980-8579, Japan \\ E-mail: o_takakuwa@mm.mech.tohoku.ac.jp
}

\begin{abstract}
Peening techniques are used to introduce compressive residual stress into the surface of a metal in order to improve the fatigue properties and resistance to stress corrosion cracking of the metal. The present paper focuses on the effect of peening on the fatigue crack growth behavior in austenitic stainless steel. An indicator which can be used to determine by how much the fatigue crack growth can be suppressed was found. Regardless of the type of peening technique used, a much closer correlation to the number of cycles to failure was found with the area of integration under the compressive residual stress curve with respect to depth than with the compressive residual stress at the surface. Moreover hybrid peening, which is a combination of different peening techniques, was developed in this study in order to enhance the favorable effects of peening. Hybrid peening increased the area of integration under the compressive residual stress curve and, as a result, a further increase in the number of cycles to failure compared to single peening was obtained.
\end{abstract}

Key words: Fatigue Crack Growth, Residual Stress, Hardness, Hybrid Peening

\section{Introduction}

Peening techniques can be applied to improve the fatigue properties of materials ${ }^{(1)-(3)}$, and to increase a material's resistance to stress corrosion cracking $^{(4)}$ or hydrogen embrittlement ${ }^{(5)-(7)}$ etc. These favorable effects can be attributed to the introduction of compressive residual stress and an increase in hardness at the surface of the material. However, the effect of these on the fatigue crack growth in metals is not yet clearly understood. In this study, an indicator by which the suppression of fatigue crack growth can be determined was found via a quantitative investigation of the fatigue crack growth behavior in austenitic stainless steel treated by several peening techniques under several different conditions. In addition to the residual stress at the surface, the residual stress profile in the depth direction was evaluated.

The impact from peening induces a plastic strain causing the surface to expand. Consequently, a reactive force is generated in the base metal. This force corresponds to the compressive residual stress. In the plastic deformation process during peening, the hardness at the surface increases. It is considered that both the introduction of compressive residual stress and an increase in hardness have an effect on crack growth behavior due to a crack closure effect and a decrease in the plastic region around the crack tip. The relationship between these changes in mechanical properties and the fatigue crack growth behavior needs to be clarified in order to develop a peening technique focused on improving the fatigue properties of metals. Several peening techniques have been developed over the past

*Received 24 Oct., 2012 (No. 12-0445) [DOI: 10.1299/jmmp.7.357]

Copyright $@ 2013$ by JSME 
few decades, such as shot peening, cavitation peening and laser peening. Shot peening utilizes the impacts arising from collisions between solid bodies induced by shot accelerated to high velocity ${ }^{(8)}$. Cavitation peening utilizes the impacts due to cavitation bubbles collapsing at the surface ${ }^{(\bullet(1)}$. Laser peening utilizes the impacts caused by a laser-driven shock wave ${ }^{(1)}$. There are large differences between these peening techniques, e.g., strain velocity ${ }^{(12)}$, plastic dimple size, and plastic deformed volume ${ }^{(13)}$. In order to combine the favorable effects from each of these, hybrid peening was developed in this study. Hybrid peening is a combination of different types of peening techniques, e.g., cavitation peening after shot peening, and it differs from double shot peening which is a combination of shot peening with different size shot, e.g., shot peening employing small shot after shot peening with large shot ${ }^{(1)}$. Hybrid peening can be used to alter the residual stress profile in the depth direction and this can have an effect on the fatigue crack growth behavior. When the effect of peening becomes saturated, overlapping it with another type of peening, i.e., hybrid peening, may produce an additional effect. In past literature, it has been reported that the fatigue strength is closely related to hardness ${ }^{(1)}$. Murakami et al. also demonstrated that the threshold level of the stress intensity factor around a micro defect or micro crack can be found from the Vickers hardness and a shape constant ${ }^{(1)}$. Since peening has a large effect on hardness, there may be a relationship between the hardness introduced by peening and the fatigue crack growth.

In this paper, fatigue crack growth tests were done using a plate bending fatigue tester on JIS SUS316L treated by several peening techniques, including shot peening, cavitation peening employing a cavitating jet in water and air, and laser peening. Moreover, hybrid peening was developed to obtain further favorable effects. The residual stress profile in the depth direction was obtained by X-ray diffraction combined with electro-polishing for layer removal. In addition, the effect of increasing the Vickers hardness by peening on the fatigue crack growth behavior was evaluated.

\section{Experimental apparatus and procedures}

Figure 1 shows the geometry and dimensions of the specimens used for the plate bending fatigue tests. The material under test was made of Japanese Industrial Standards JIS SUS316L austenitic stainless steel. The specimens were thermally refined to remove any pre-strain. The yield strength, defined as $0.2 \%$ offset stress, and the tensile strength were $304 \mathrm{MPa}$ and $576 \mathrm{MPa}$, respectively. The notch, $2 \mathrm{~mm}$ in length, $0.5 \mathrm{~mm}$ wide and with a depth of $0.5 \mathrm{~mm}$, was produced by mechanical machining after peening. The bending stress was generated by eccentric rotation which was set to $600 \mathrm{rpm}$. The plate bending fatigue test was conducted with an initial bending stress of $350 \mathrm{MPa}$ by controlling the displacement rather than the load. The initial stress ratio was $R=-1$. The length of the crack was observed every 2,000 or 4,000 cycles using a camera.

The compressive residual stress was measured using an X-ray diffraction method, i.e., the $\sin ^{2} \psi$ method, employing an X-ray tube with a $\mathrm{Cr}$ target operated at $30 \mathrm{kV}$ and $8 \mathrm{~mA}$. $\mathrm{X}$-rays from the $\mathrm{K} \beta$ peak were used. The angle of the soller slit was 1 degree and the slit

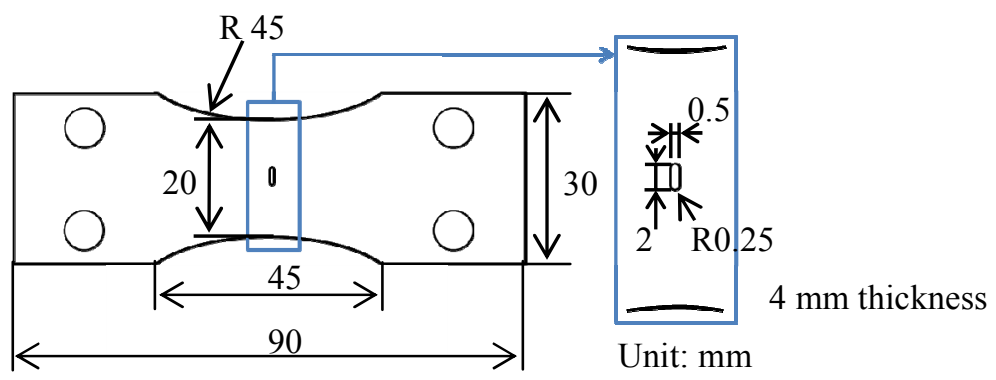

Fig. 1 Geometry and dimensions of the specimens used for the plate bending fatigue test 
width was $4 \mathrm{~mm}$. In this study, the diffractive plane was the $\left(\begin{array}{lll}3 & 1 & 1\end{array}\right)$ plane of $\gamma$-Fe, and the diffractive angle without strain $2 \theta_{0}$ was 148.5 degrees. Diffractive angle measurements from 143.5 to 153.5 degrees in steps of 0.2 degrees were made. The diffracted X-rays were counted for $3 \mathrm{sec}$. for each step using a scintillation counter at angles of $\psi=0,22.8,33.2$, 42.2 and 50.8 degrees. The stress factor was $-368.9 \mathrm{MPa} / \mathrm{deg}$. In order to verify the effect of Vickers hardness varied by each peening on the fatigue crack growth, Vickers hardness tests were conducted seven times at the surface of each specimen sing a micro hardness tester HMV-1 (Shimadzu Corporation). The maximum load was set to $P_{\max }=1.961 \mathrm{~N}$. The results for Vickers hardness were obtained as the average of five sets of experimental data with expecting maximum and minimum value.

Figure 2 shows a schematic diagram of the head used for shot peening (SP) employing re-circulating shot accelerated by a water jet ${ }^{(8)}$. The shot used in the present study were metallic particles made of Japan Industries Standards (JIS) SUS440C. The diameter and number of shot were $3.2 \mathrm{~mm}$ and 700, respectively. The water jet was pressurized to $8 \mathrm{MPa}$ by a plunger pump, and the standoff distance between the specimen surface and the nozzle was set to $45 \mathrm{~mm}$. The optimization of these conditions has been discussed in a previous report $^{(8)}$. The processing time is defined by the number of scans, $n$, and the velocity of the scan, $v$, as follows:

$$
t_{p}=\frac{n}{v}
$$

In SP, various processing times per unit length, $t_{p}$, were used, the values being $1,2,3,4,6$, 8 and $10 \mathrm{~s} / \mathrm{mm}$.

Figure 3 shows schematic diagrams of the nozzles used for cavitation peening employing a cavitating jet in water ${ }^{(17)}(\mathrm{CPW})$ and a cavitating jet in air ${ }^{(18)}$ (CPA). In cavitation peening, a high-speed water jet is injected into a water filled tank (cavitating jet in water) or a low-speed water jet injected into air (cavitating jet in air). For both the cavitating jet in water and in air, the pressure of the high-speed water jet was $30 \mathrm{MPa}$. Although, in general, a water filled tank is needed to realize a cavitating jet, it is not needed in the case of a cavitating jet in air since the cavitating jet can be realized by a low-speed water jet. The experimental conditions for both cavitating jets are shown in Table 1. These conditions have been optimized in previous experimental research and have been reported in the literature $^{(17)(18)}$. The processing time per unit length given by Eq. (1) was varied, with $t_{p}=8$, 16 and $30 \mathrm{~s} / \mathrm{mm}$ and $t_{p}=2,10,20$ and $30 \mathrm{~s} / \mathrm{mm}$ for CPW and CPA, respectively.

Laser peening utilizes the impact caused by a laser-driven shock wave. When the surface of a material is irradiated with a high power pulsed laser such as a Nd: YAG laser in water, the surface evaporates through ablation. This gives rise to a plasma at the surface, and the

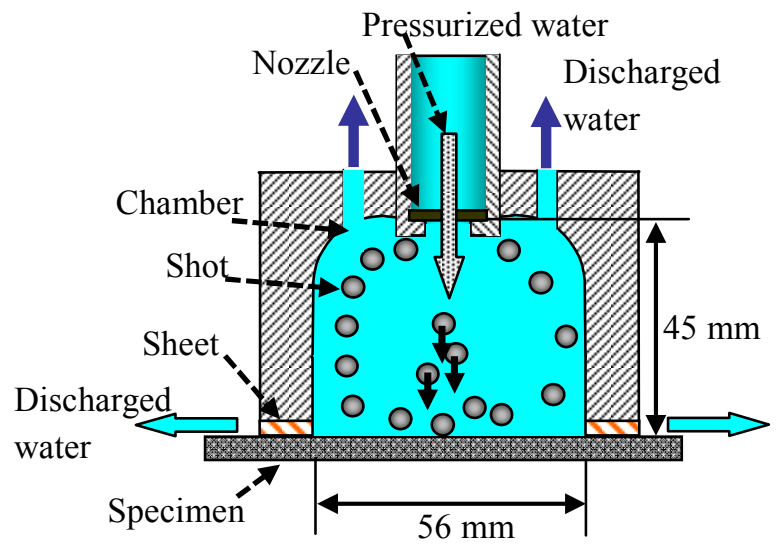

Fig. 2 Schematic diagram of shot peening apparatus 


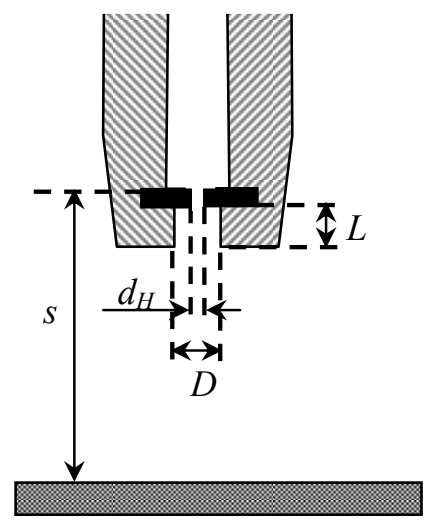

(a) Cavitating jet in water (for CPW)

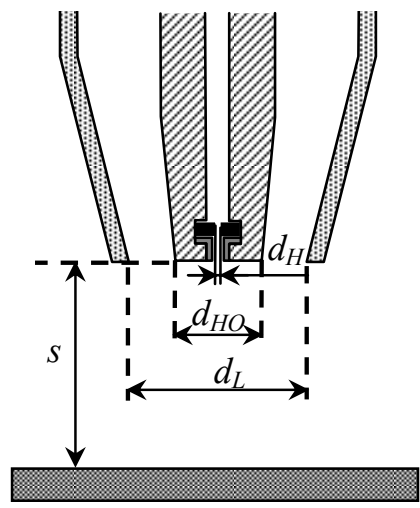

(b) Cavitating jet in air (for CPA)

Fig. 3 Schematic diagram of nozzle for the cavitating jet

Table 1 Conditions of the cavitating jets ${ }^{(17)(18)}$

\begin{tabular}{c|c|c}
\hline & \multicolumn{2}{|c}{ Cavitating jet } \\
\cline { 2 - 3 } & in water ${ }^{(17)}$ & in air ${ }^{(18)}$ \\
\hline $\begin{array}{c}\text { Pressure of high-speed } \\
\text { water jet } p_{H} \mathrm{MPa}\end{array}$ & 30 & 30 \\
\hline $\begin{array}{c}\text { Pressure of low-speed } \\
\text { water jet } p_{L} \mathrm{MPa}\end{array}$ & - & 0.05 \\
\hline $\begin{array}{c}\text { Nozzle diameter for high-speed } \\
\text { water jet } d_{H} \text { mm }\end{array}$ & 2 & 1 \\
\hline $\begin{array}{c}\text { Nozzle diameter for low-speed } \\
\text { water jet } d_{L} \text { mm }\end{array}$ & - & 30 \\
\hline $\begin{array}{c}\text { Nozzle outlet diameter for high-speed } \\
\text { water jet } d_{H O} \text { mm }\end{array}$ & - & 16 \\
\hline Nozzle outlet bore diameter $D$ mm & 16 & - \\
\hline Nozzle outlet bore length $L \mathrm{~mm}$ & 16 & 45 \\
\hline Standoff distance $s$ mm & 162 & \\
\hline
\end{tabular}

focused laser energy transmitting through the plasma causes a shock wave, with an intensity of the order of gigapascals, to develop. In this study, laser peening was conducted in water by employing a Nd:YAG laser with a wavelength and pulse energy of $1.06 \mu \mathrm{m}$ and $200 \mathrm{~mJ}$, respectively. The wavelength changed to $532 \mathrm{~nm}$ in water. The apparatus for laser peening was developed by the TOSHIBA Corporation ${ }^{(4)}$. The laser was focused via a plano-convex lens. The pulse number density and spot diameter were 36 pulse $/ \mathrm{mm}^{2}$ and $0.8 \mathrm{~mm}$, respectively. The surface was irradiated by the laser as shown in Fig. 4.

In this study, hybrid peening was realized through combinations of SP, CPW and CPA, as shown in Table 2. The processing time for each peening method was determined by the point at which the effect of the peening method on the fatigue crack growth became saturated. This is described in Section 3.

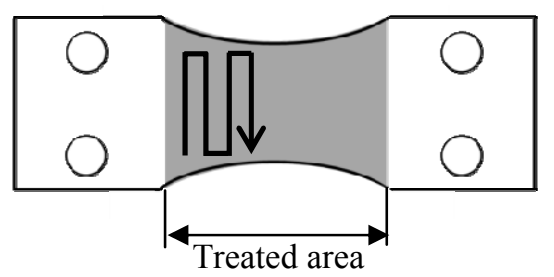

Fig. 4 Direction of treatment using laser peening 
Table 2 Combinations in hybrid peening

\begin{tabular}{c|c|c|c}
\hline Specimen & Symbol & Former process & Latter process \\
\hline \multirow{2}{*}{$\begin{array}{c}\text { HP A } \\
\text { group }\end{array}$} & HP-A1 & $\begin{array}{c}\text { Cavitation peening employing } \\
\text { a cavitating jet in water (CPW) }\end{array}$ & $\begin{array}{c}\text { Cavitation peening employing } \\
\text { a cavitating jet in air (CPA) }\end{array}$ \\
\cline { 2 - 4 } & HP-A2 & $\begin{array}{c}\text { Cavitation peening employing } \\
\text { a cavitating jet in air (CPA) }\end{array}$ & $\begin{array}{c}\text { Cavitation peening employing } \\
\text { a cavitating jet in water (CPW) }\end{array}$ \\
\hline \multirow{2}{*}{$\begin{array}{c}\text { HP B } \\
\text { group }\end{array}$} & HP-B1 & $\begin{array}{c}\text { Cavitation peening employing } \\
\text { a cavitating jet in water (CPW) }\end{array}$ & $\begin{array}{c}\text { Shot peening } \\
\text { (SP) }\end{array}$ \\
\cline { 2 - 4 } & HP-B2 & $\begin{array}{c}\text { Shot peening } \\
\text { (SP) }\end{array}$ & $\begin{array}{c}\text { Cavitation peening employing } \\
\text { a cavitating jet in water (CPW) }\end{array}$ \\
\hline \multirow{2}{*}{$\begin{array}{c}\text { HP C } \\
\text { group }\end{array}$} & HP-C1 & $\begin{array}{c}\text { Cavitation peening employing } \\
\text { a cavitating jet in air (CPA) }\end{array}$ & $\begin{array}{c}\text { Shot peening } \\
\text { (SP) }\end{array}$ \\
\cline { 2 - 4 } & HP-C2 & $\begin{array}{c}\text { Shot peening } \\
\text { (SP) }\end{array}$ & $\begin{array}{c}\text { Cavitation peening employing } \\
\text { a cavitating jet in air (CPA) }\end{array}$ \\
\hline
\end{tabular}

\section{Results and discussion}

Figure 5 shows the fatigue crack length, $2 a$, as a function of the number of cycles, $N$, in a non-treated specimen and specimens treated by shot peening (SP), cavitation peening employing a cavitating jet in water (CPW), a cavitating jet in air (CPA), and laser peening (LP). Figure 6 plots the number of cycles to failure, $N_{f}$, and the fatigue crack growth rate, $d a / d N$, at half the number of cycles to failure, i.e., $N / N_{f}=0.5$, as a function of the processing time per unit length, $t_{p}$, for each specimen. These results clearly demonstrate that the fatigue crack growth is suppressed by peening regardless of the type of peening used, and also demonstrate that increasing the processing time increases the resistance to fatigue crack growth. The fatigue crack growth rate, $d a / d N$, at $N / N_{f}=0.5$ and the number of cycles to failure, $N_{f}$, of a non-treated specimen, i.e., $t_{p}=0 \mathrm{~s} / \mathrm{mm}$, are $3.4 \times 10^{-7} \mathrm{~m} /$ cycle and 29,800 cycles, respectively. In the specimens treated by SP, $d a / d N$ at $N / N_{f}=0.5$ becomes saturated at $7 \times 10^{-8} \mathrm{~m} /$ cycle when $t_{p}$ is equal to or greater than $4 \mathrm{~s} / \mathrm{mm}$. $N_{f}$ increases from 29,800 to 100,300 cycles with SP $\left(t_{p}=4 \mathrm{~s} / \mathrm{mm}\right)$. In the specimens treated by CPW and CPA, $d a / d N$ at $N / N_{f}=0.5$ becomes saturated at $1.5 \times 10^{-7}$ and $1.8 \times 10^{-7} \mathrm{~m} /$ cycle when $t_{p}=16$ and $20 \mathrm{~s} / \mathrm{mm}$, respectively. $N_{f}$ increases to 60,300 and 56,000 cycles with CPW $\left(t_{p}=16 \mathrm{~s} / \mathrm{mm}\right)$ and CPA $\left(t_{p}\right.$ $=20 \mathrm{~s} / \mathrm{mm})$, respectively. The results indicate the largest decrease in the fatigue crack growth rate is for the specimen treated by LP, i.e., $d a / d N=5.0 \times 10^{-8} \mathrm{~m} /$ cycle and $N_{f}=$

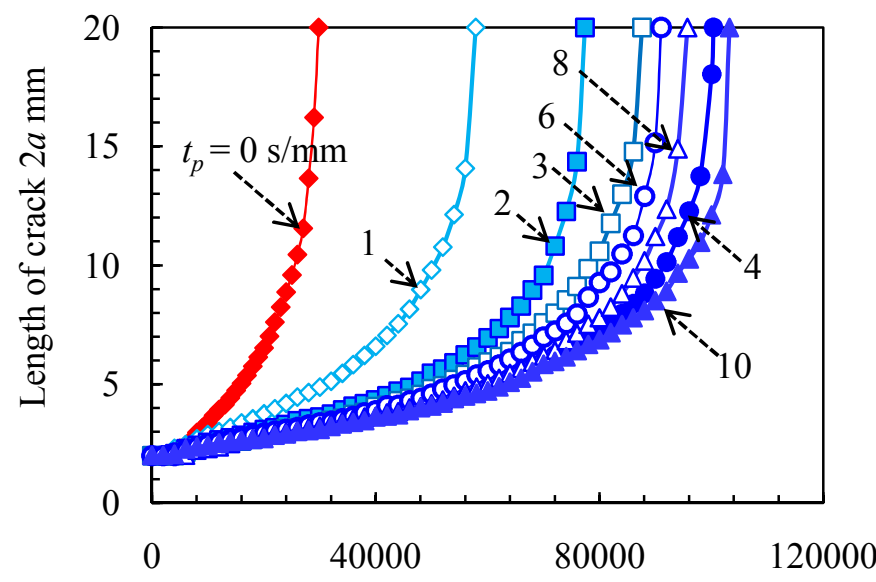

Number of cycles $N$

(a) Shot peening (SP)

Fig. 5 Fatigue crack growth behavior in SUS316L treated by shot peening, cavitation peening and laser peening 


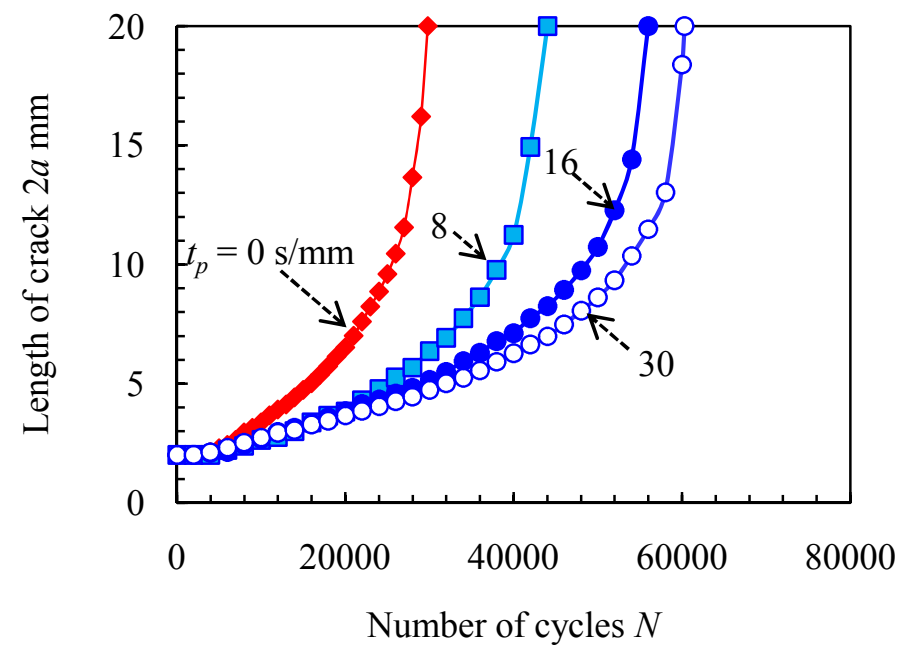

(b) Cavitation peening employing a cavitating jet in water (CPW)

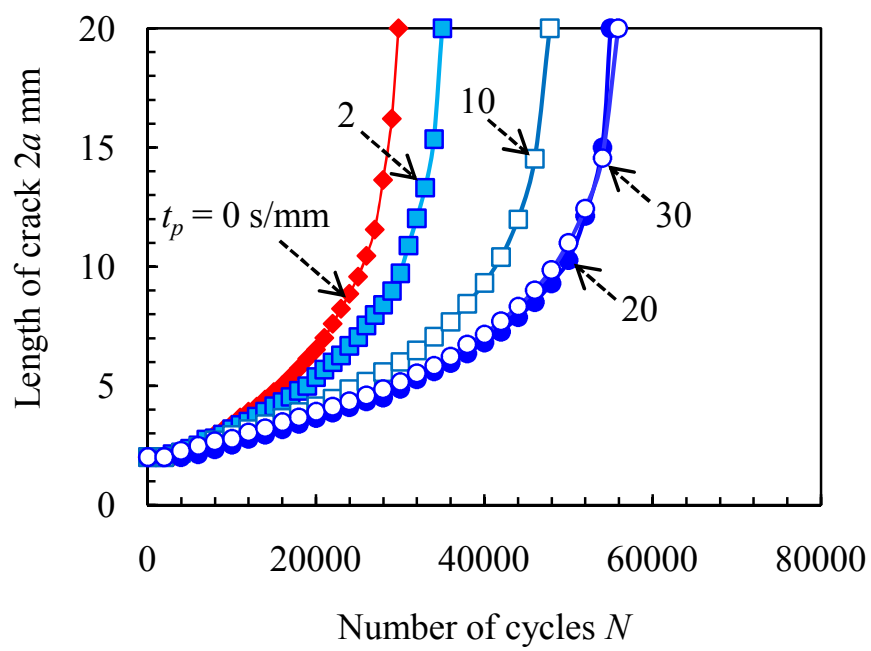

(c) Cavitation peening employing a cavitating jet in Air (CPA)

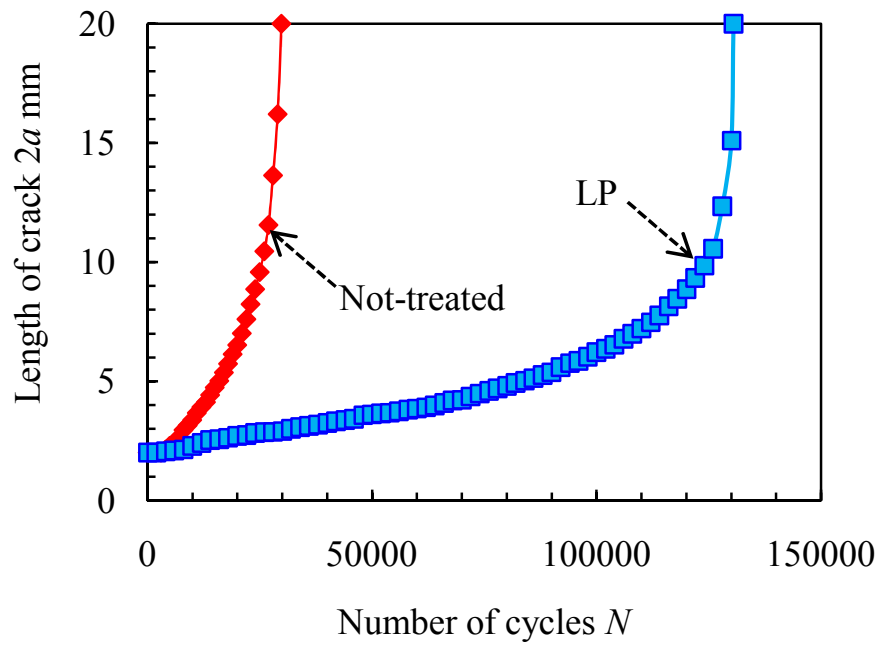

(d) Laser peening (LP)

Fig. 5 Fatigue crack growth behavior in SUS316L treated by shot peening, cavitation peening and laser peening (Continued) 


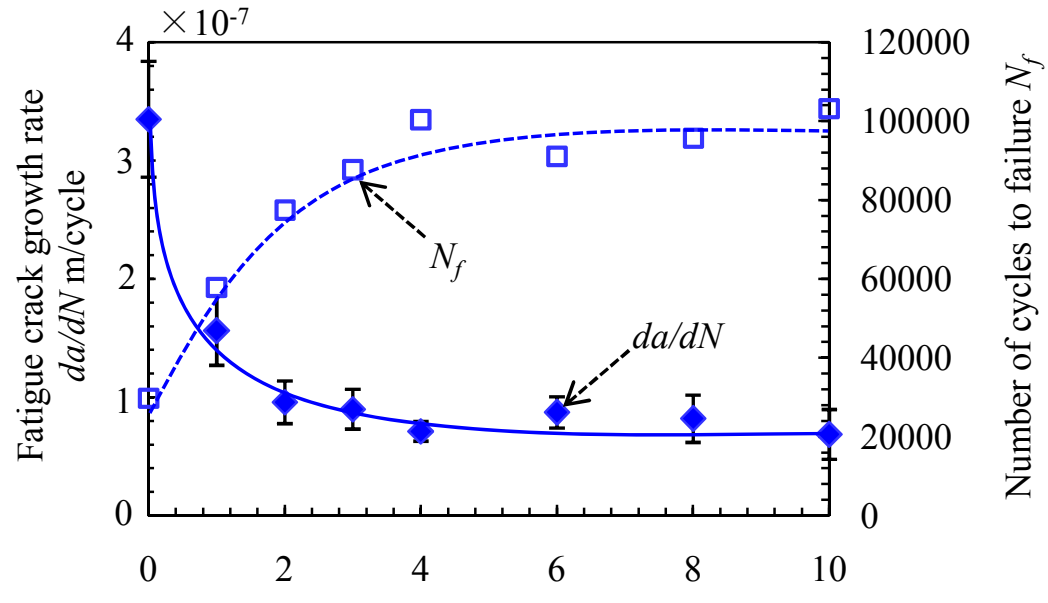

Processing time per unit length $t_{p} \mathrm{~s} / \mathrm{mm}$

(a) Shot peening (SP)

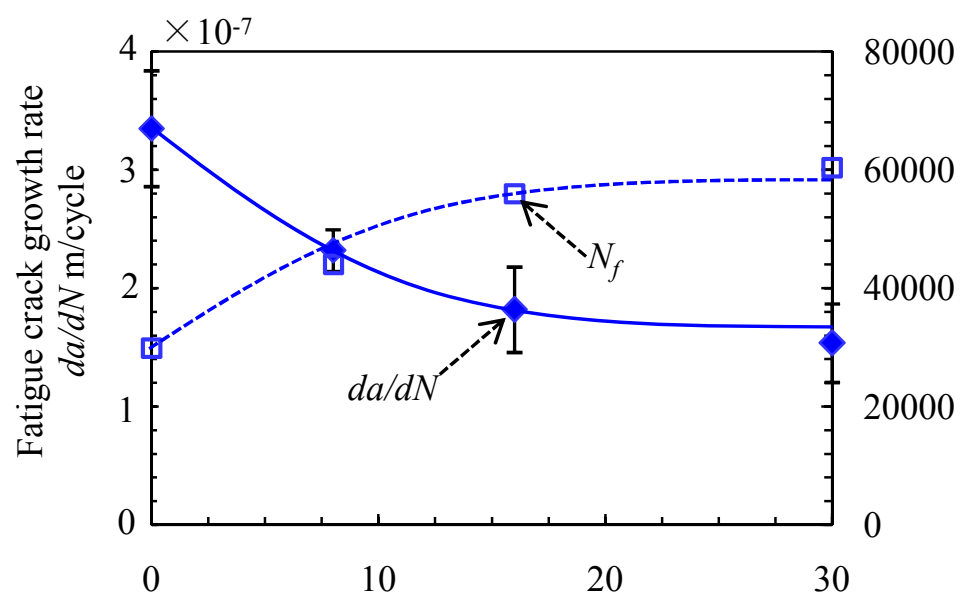

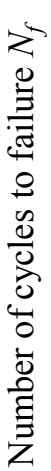

Processing time per unit length $t_{p} \mathrm{~s} / \mathrm{mm}$

(b) Cavitation peening employing a cavitating jet in water (CPW)

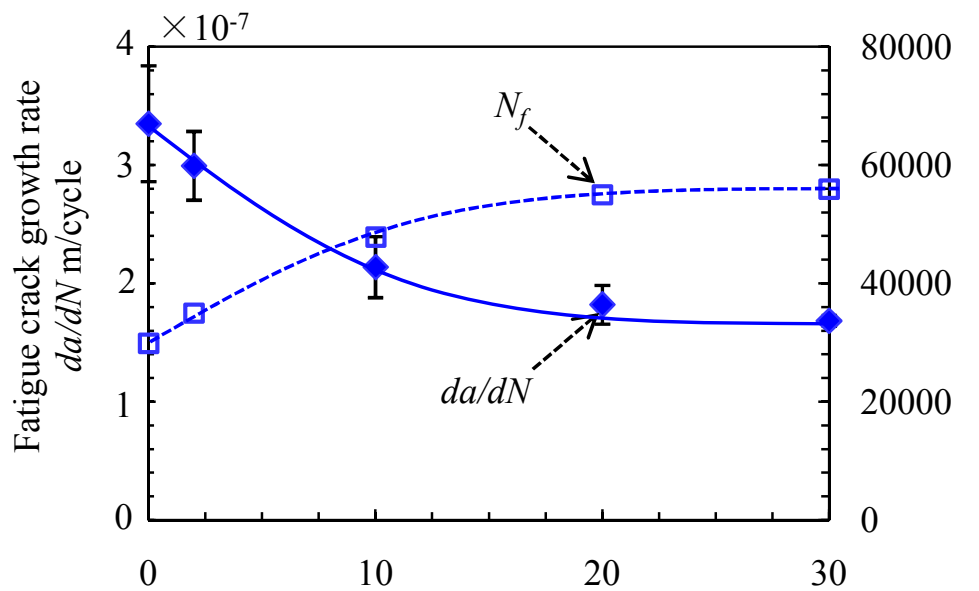

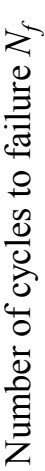

Processing time per unit length $t_{p} \mathrm{~s} / \mathrm{mm}$

(c) Cavitation peening employing a cavitating jet in air (CPA)

Fig. 6 Variation of fatigue crack growth rate and number of cycles to failure with processing time 
130,500 cycles. These differences in resistance to fatigue crack growth can be attributed to the introduction of different amounts of compressive residual stress. Moreover, the results show that the optimum processing times for hybrid peening are $t_{p}=4 \mathrm{~s} / \mathrm{mm}$ for SP, $16 \mathrm{~s} / \mathrm{mm}$ for $\mathrm{CPW}$ and $20 \mathrm{~s} / \mathrm{mm}$ for CPA. In the following section we discuss the fatigue crack growth behavior after treatment by hybrid peening with combinations of these processing times.

Figure 7 shows the fatigue crack length, $2 a$, as a function of the number of cycles, $N$, in the specimens treated by each hybrid peening method. The symbols, such as HP-A1 for instance, are defined in Table 2. As shown in Fig. 7, a greater resistance to fatigue crack growth was obtained in all specimens treated by hybrid peening compared with the specimens treated by a single peening method. The number of cycles to failure, $N_{f}$, in specimens individually treated by CPW and CPA become almost saturated at 56,000 and 60,000 cycles, respectively. However, $N_{f}$ increases to 72,000 (HP-A1: CPW+CPA) and 80,000 (HP-A2: CPA+CPW) cycles when these treatments are combined. The same tendency appears in the combinations of shot peening and cavitation peening as shown in Figs. 7(b) and (c). For HP-B1 (CPW+SP) and HP-B2 (SP+CPW), $N_{f}$ increases from 60,000 to 130,000 and from 100,000 to 120,000 cycles, respectively. In addition, for HP-C1 $(\mathrm{CPA}+\mathrm{SP})$ and HP-C2 (SP+CPA), $N_{f}$ increases from 56,000 to 130,000 and from 100,000 to

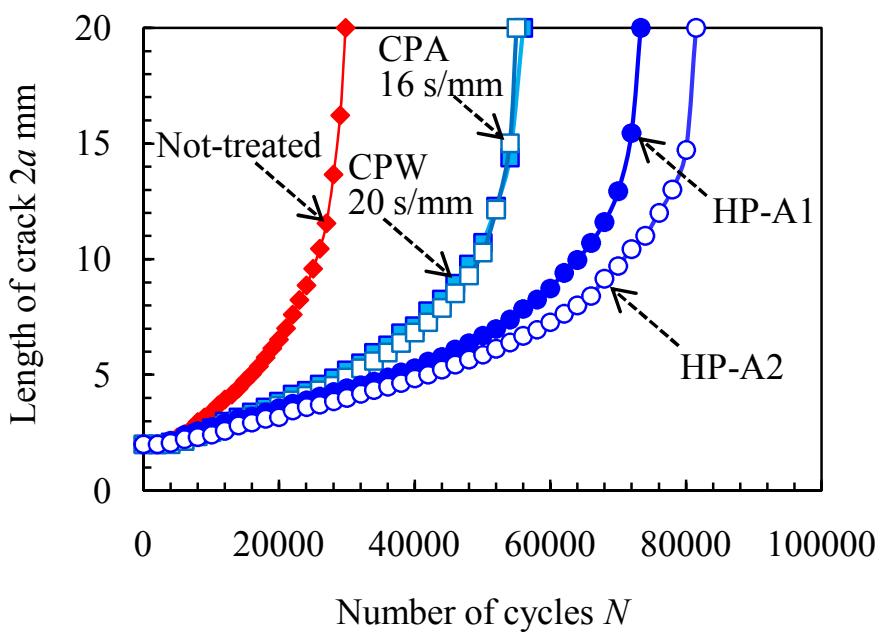

(a) Combination of cavitation peening employing a cavitating jet in water $(\mathrm{CPW})$ and air (CPA): HP-A group

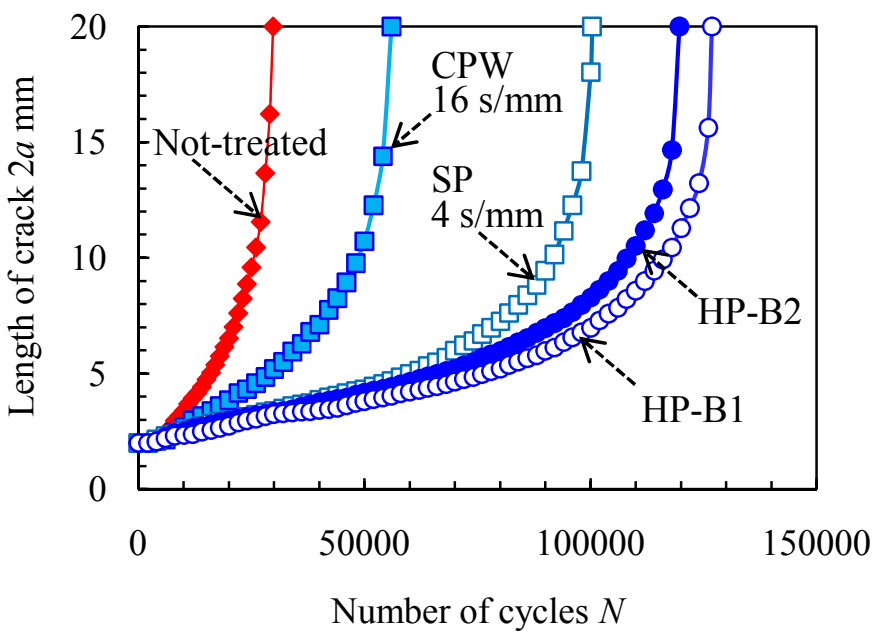

(b) Combination of shot peening (SP) and cavitation peening employing a cavitating jet in air (CPW): HP-B group

Fig. 7 Fatigue crack growth behavior in SUS316L treated by hybrid peening 


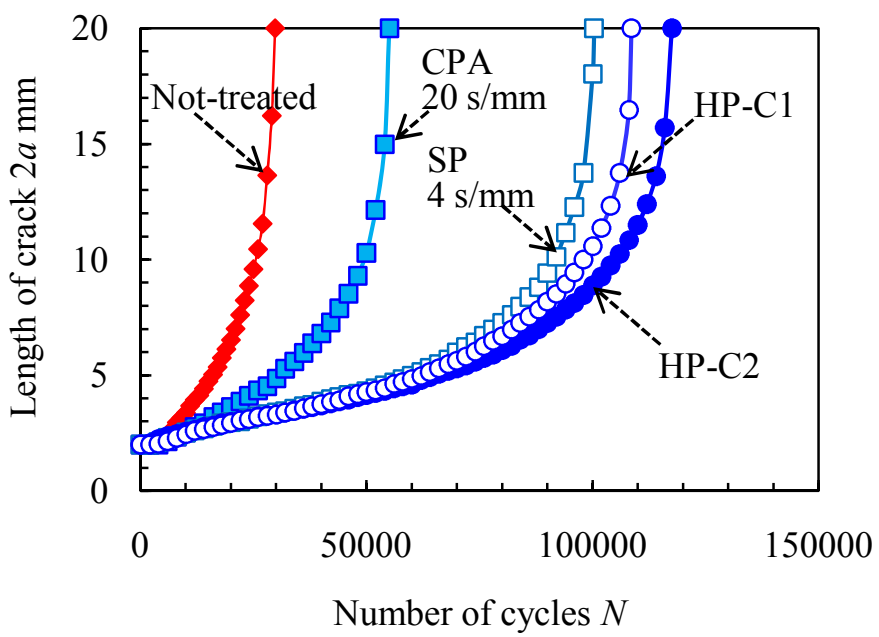

(c) Combination of shot peening (SP) and cavitation peening employing a cavitating jet in water (CPA): HP-C group

Fig. 7 Fatigue crack growth behavior in SUS316L treated by hybrid peening (Continued)

120,000 cycles, respectively. It is likely that the increase in the resistance to fatigue crack growth due to hybrid peening depends on peening effects such as the introduction of compressive residual stress and the increase in hardness. In order to obtain an indicator for the suppression of fatigue crack growth realized by peening, the relationships between these peening effects and the crack growth behavior are described in the following paragraph.

Figure 8 plots depth profiles of the compressive residual stress in each specimen obtained via X-ray diffraction in combination with electro-polishing excepting cavitation peening employing a cavitating jet in air (CPA), which has already reported in past literature ${ }^{(10)}$. The depth profiles for SP $\left(t_{p}=1\right.$ and $\left.4 \mathrm{~s} / \mathrm{mm}\right)$ and LP are plotted in Fig. 8(a), and for CPW ( $t_{p}=$ 8,16 and $30 \mathrm{~s} / \mathrm{mm}$ ) and for HP are also plotted in Fig. 8(b) and (c), respectively. The shape of the depth profiles depends on type of peening. In a case of the specimens treated by SP and/or LP have maximum value at not the surface but certain depth due to Hertz contact. CP introduces the compressive residual stress linearly with respect to the depth due to its randomness of aggressivity of the impact generated by cavitation bubble collapsing. In regarding the depth profile of the compressive residual stress for SP, both the compressive residual stress at the surface, $\sigma$, and its depth are not saturated at $t_{p}=1 \mathrm{~s} / \mathrm{mm}$ as shown in Fig. 8(a), but those values become saturated after treatment with more processing time. In contrast, although $\sigma$ is almost saturated at $t_{p}=8 \mathrm{~s} / \mathrm{mm}$ for CPW, its depth does not become saturated as shown in Fig. 8(b). It can be explained by a relationship between frequency and aggressivity of the impacts which induce the compressive residual stress. The frequency related to density of the plastic deformation pits and the aggressivity of impacts related to size of the plastic deformation pit have a dominant effect on the compressive residual stress at the sub-surface and its depth, respectively. To summarize this point, if the compressive residual stress becomes saturated at the surface, its depth increases when the surface is subjected to large impacts whose frequency increases with increase in the processing time. Since the introduction of compressive residual stress differs according to the type of peening, three parameters obtained by the depth profile were considered in following paragraph in order to find a useful indicator for determining the suppression of fatigue crack growth.

Figures 9(a) and (b) plot the number of cycles to failure, $N_{f}$, as a function of the compressive residual stress at the surface, $\sigma$, and the depth of it from the surface, $d_{c}$, respectively, for several specimens. In Figs. 9(a) and (b), although there is a tendency for higher compressive residual stress at the surface and deeper compressive residual stress to yield greater resistance to fatigue crack growth, the correlation with $N_{f}$ is poor when all the different peening methods are considered. For CPA, for instance, $N_{f}$ increases from 35,000 to 56,000 cycles as $\sigma$ varies from $371 \mathrm{MPa}$ at a processing time of $2 \mathrm{~s} / \mathrm{mm}$ to $518 \mathrm{MPa}$ at $20 \mathrm{~s} / \mathrm{mm}$. On the other hand, for CPW, $N_{f}$ is higher than that of CPA in spite of lower $\sigma$. It is likely that CPW introduces compressive residual stress to a greater depth than CPA as 


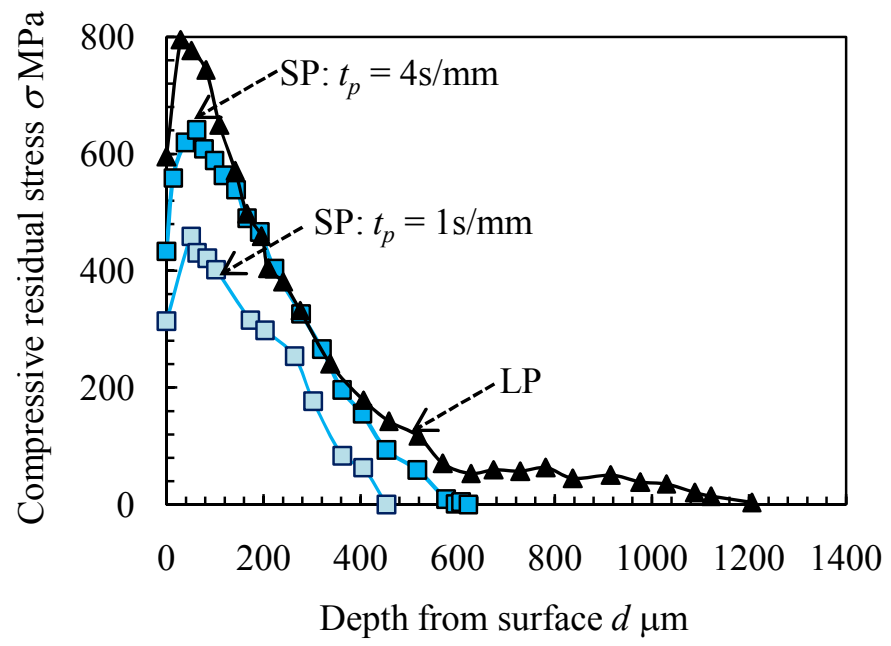

(a) Shot peening (SP) and Laser peening (LP)

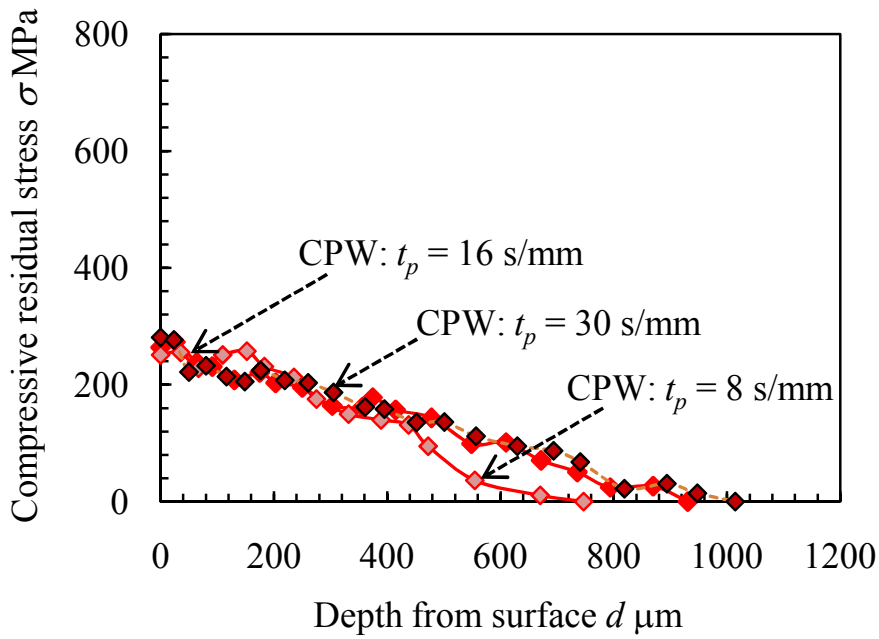

(b) Cavitation peening employing a cavitating jet in water (CPW)

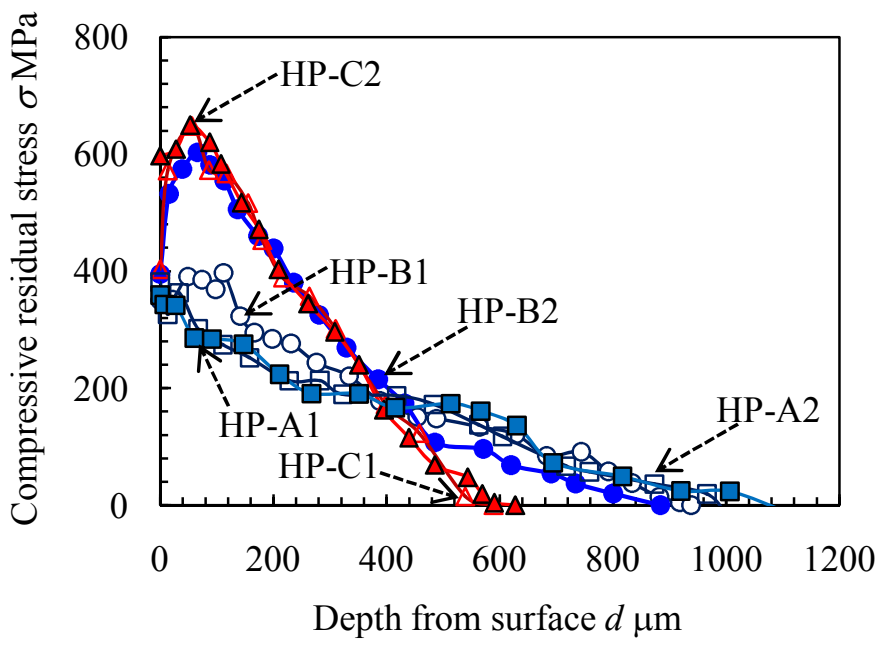

(c) Hybrid peening (HP)

Fig. 8 Depth profiles of the compressive residual stress 
shown in Fig. 9(b).

Figure 9(c) plots the number of cycles to failure, $N_{f}$, as a function of the area of integration under the compressive residual stress curve with respect to depth, $S_{\sigma}$, for all specimens. The depth profile for CPA was obtained by reference to previous literature ${ }^{(10)}$. As shown in Fig. 9(c), $N_{f}$ increases linearly with increasing $S_{\sigma}$, with a gradient of $1.67 \pm$ 0.11 , regardless of the type of peening technique used. The correlation coefficient $R$ for this plot is $0.95 . N_{f}$ increases, for instance, from 35,000 at $S_{\sigma}=64,000$ (CPA: $t_{p}=2 \mathrm{~s} / \mathrm{mm}$ ) to 130,000 cycles at $S_{\sigma}=202,000 \mathrm{MPa} \mu \mathrm{m}(\mathrm{HP}-\mathrm{B} 1: \mathrm{CPW}+\mathrm{SP})$. Thus, the increase in $N_{f}$ after hybrid peening results from the increase in $S_{\sigma}$.

The fatigue crack keeps semielliptical shape while growing both along the surface and in the depth direction due to the applied bending stress as a driving force of the fatigue crack growth. When the fatigue crack grows in the treated specimens, it keeps same shape with the not-treated specimen, i.e., same aspect ratio of the crack length growing along the surface to that in the depth ${ }^{(19)}$. The compressive residual stress decreases crack opening displacement, so-called crack closure effect, and this affects the stress intensity factor around a crack tip ${ }^{(20)}$. Thus the compressive residual stress introduced by peening is considered to be a major factor to suppress the fatigue crack growth. The suppressive effect of the compressive residual stress on the fatigue crack growth needs to be examined in terms of the depth profiles of the compressive residual stress as well as its value at the surface since the fatigue crack grows both along the surface and in the depth with the semielliptical shape as above stated. Therefore, in the present paper, the area of compressive residual stress in depth was defined as an indicator for the suppression of the fatigue crack growth by peening from a viewpoint of a resistance of metal treated by peening to the fatigue crack growth. The compressive residual stress at the surface can simply be above indicator when only one peening method is considered as shown in Fig. 9(a). It is because the area of compressive residual stress in depth varies corresponding to it at the surface with a change in the processing time. That is, in this case, the depth profile keeps same shape, e.g., the case of shot peening as shown in Fig. 8(a). On the other hand, the compressive residual stress at the surface is not enough to be defined as the indicator when several types of peening are considered since the depth profiles differ totally from those types as shown in Fig. 8(c). The relationship between the shape of the profile of the compressive residual stress and suppressive effect on the fatigue crack growth should be discussed. In this study, the suppressive effect on the fatigue crack growth can be considered as a total resistance of treated specimens to the fatigue crack growth, which is attributed to the area of compressive residual stress in the depth, interacting during the fatigue process. Therefore, in this case, the area of compressive residual stress in depth taking account for the depth profile has a

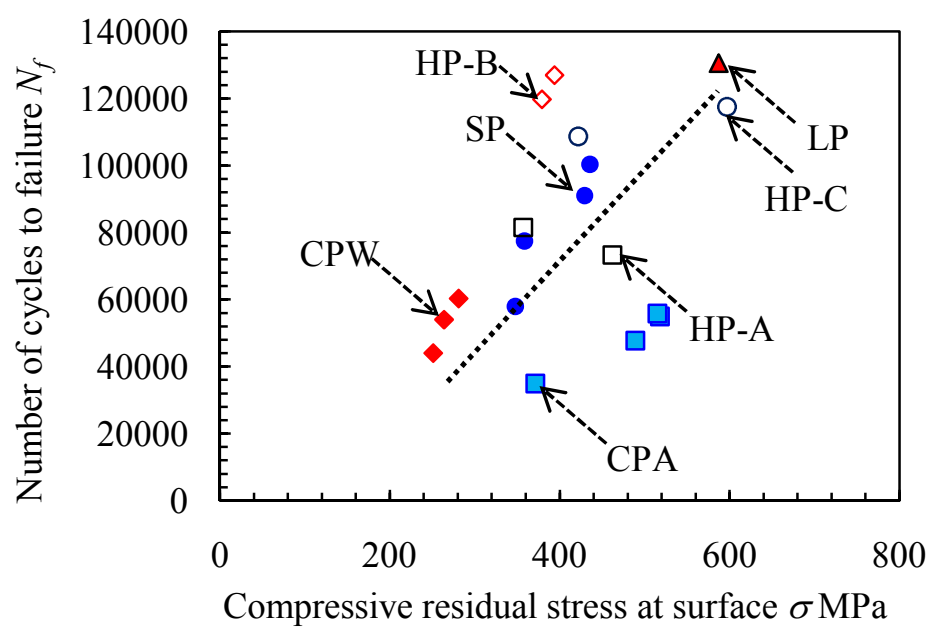

(a) Compressive residual stress at surface

Fig. 9 Indicators for the suppression of fatigue crack growth by peening 


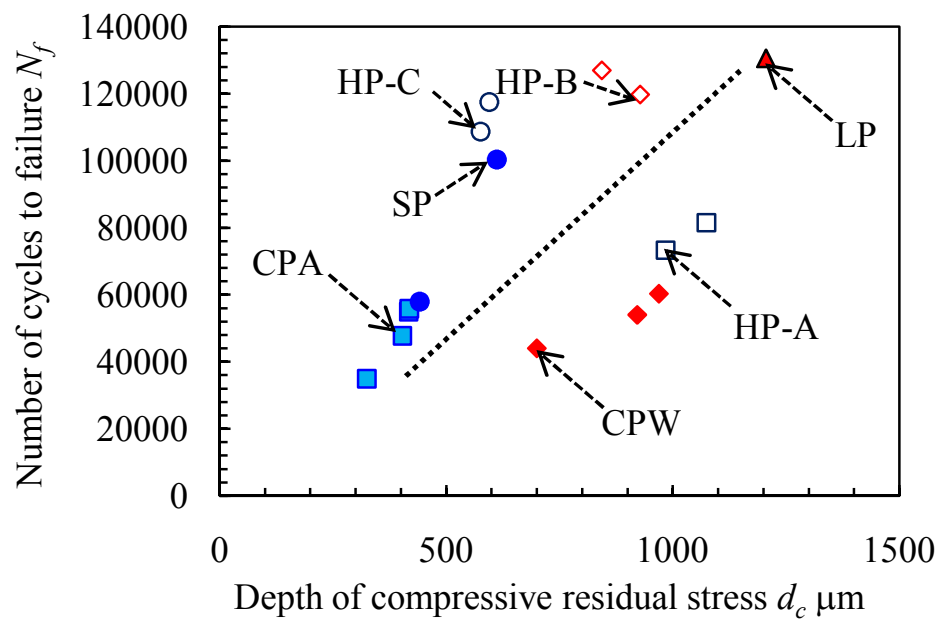

(b) Depth of compressive residual stress

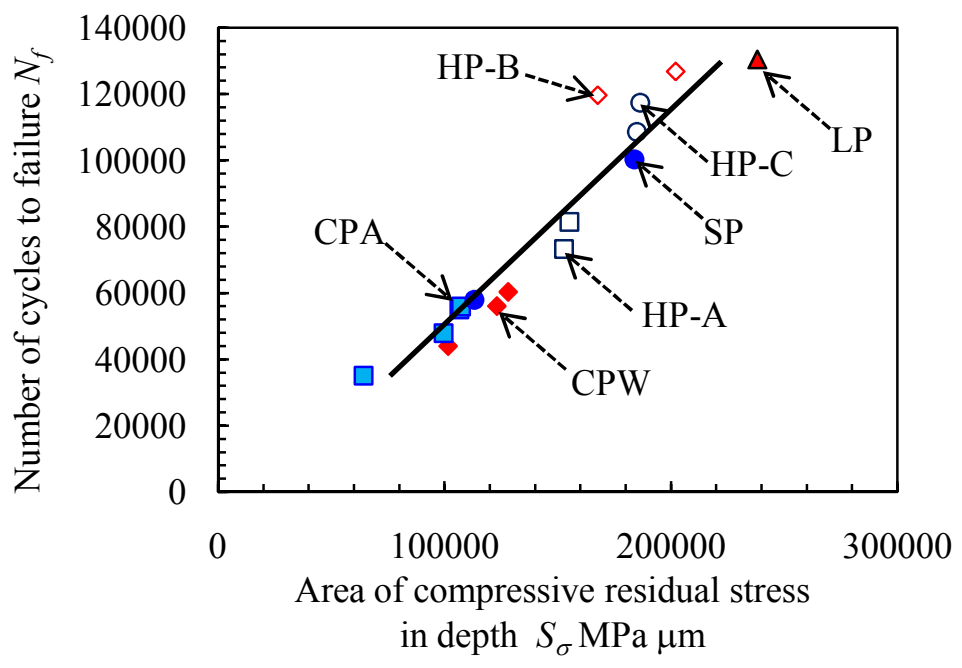

(c) Area of compressive residual stress in depth

Fig. 9 Indicators for the suppression of fatigue crack growth by peening (Continued)

possibility of being the indicator even though the most effective phase for the suppression of the fatigue crack growth differs by the shape of the depth profile.

The area of integration under the curve changes with each peening method. The depth profiles of the compressive residual stress for specimens treated by SP $\left(t_{p}=4 \mathrm{~s} / \mathrm{mm}\right), \mathrm{CPW}$ $\left(t_{p}=16 \mathrm{~s} / \mathrm{mm}\right), \mathrm{HP}-\mathrm{B} 1(\mathrm{CPW}+\mathrm{SP}), \mathrm{HP}-\mathrm{B} 2(\mathrm{SP}+\mathrm{CPW})$ are plotted in Fig. 10. Comparison of the depth profiles for SP and CPW show that SP introduces a higher compressive residual stress near the surface and CPW introduces it deeper $\left(d_{c}=883 \mu \mathrm{m}\right)$. For hybrid peening, the order of the process significantly affects the depth profile. The depth profile for HP-B1 $(\mathrm{CPW}+\mathrm{SP})$ shows the characteristics of each individual peening process combining well together. Although treatment by CPW after SP, i.e., HP-B2, introduces compressive residual stress to a greater depth, this decreases near the surface. On the other hand, a compressive residual stress of $640 \mathrm{MPa}$ at $d_{c}=61 \mu \mathrm{m}$ and stress up to a depth of $d_{c}=883 \mu \mathrm{m}$ are realized. The hybrid peening processes further increase the resistance to fatigue crack growth, as shown in Fig. 7, due to the introduction of higher and deeper compressive residual stress, i.e., increasing the area of integration under the curve compared to single peening processes. Changing the depth profile of the compressive residual stress has also been reported for double-shot peening, which utilizes a combination of small and large shot. This can give good characteristics. However, a combination of entirely different peening techniques with complementary characteristics might realize better overall characteristics. 


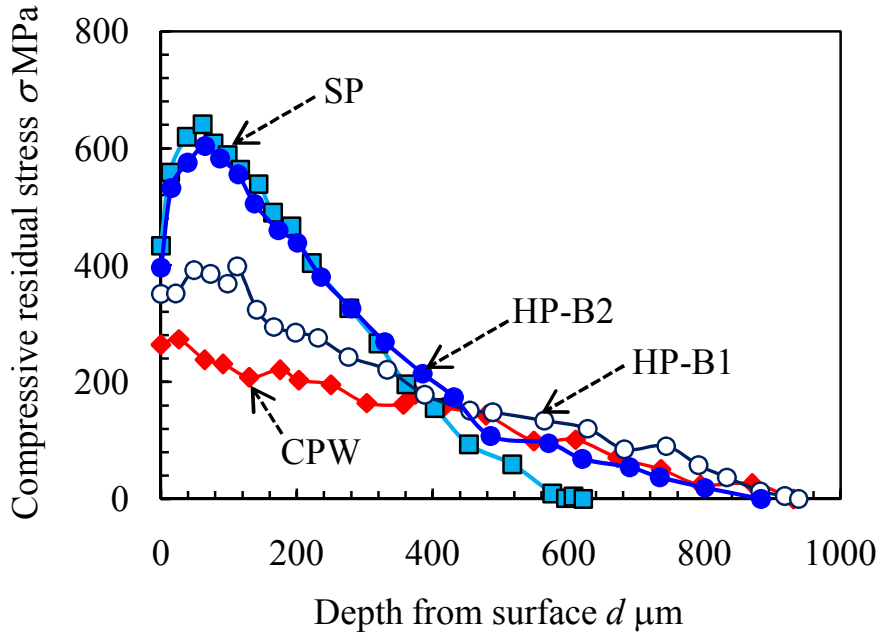

Fig. 10 Depth profiles of the compressive residual stress focused on hybrid peening

Finally, it has been reported that the fatigue strength obtained by the so-called $S-N$ curve can be evaluated experimentally by the Vickers hardness ${ }^{(15)}$. In order to show the relationship between the improvement in resistance to fatigue crack growth and the increase in Vickers hardness by peening, the number of cycles to failure, $N_{f}$, as a function of Vickers hardness, $H_{V}$, is plotted in Fig. 11 for all specimens. As shown in Fig. 11, $N_{f}$ increases with increasing $H_{V}$ regardless of the type of peening technique, similar to the results in Fig. 9(c). This is because the Vickers hardness depends not only on the compressive residual stress at the surface but also on the depth profile. Naturally, the increase in yield stress for each peening technique also affects the Vickers hardness. Therefore, this result indicates that the resistance to fatigue crack growth can be evaluated quantitatively by the Vickers hardness since it includes information regarding the depth profile of the compressive residual stress and the yield stress. The reason why this relationship is not linear, unlike that in Fig. 9(c), is because the Vickers hardness does not include as much information on the greater depths due to its limited indentation depth.

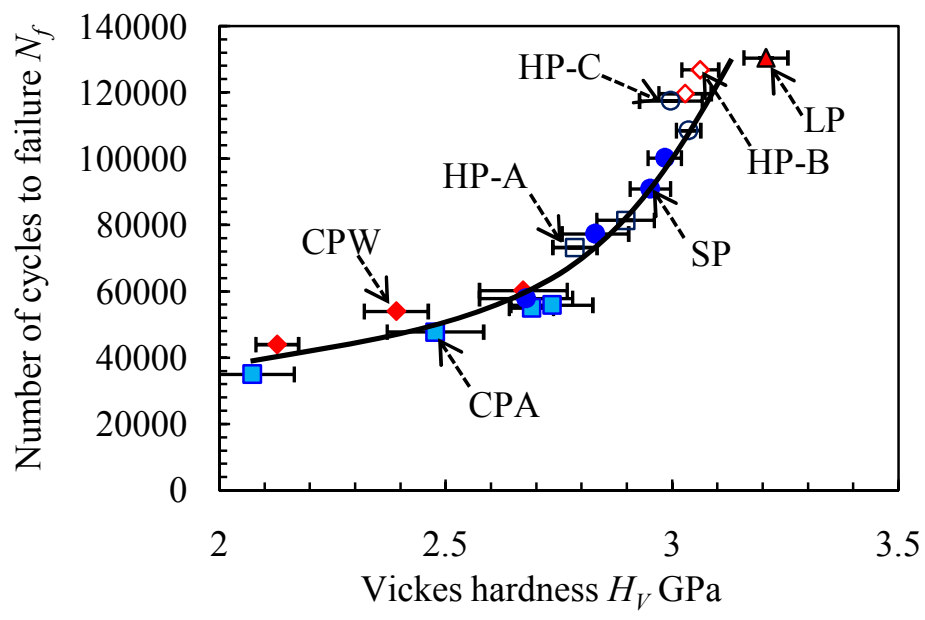

Fig. 11 Increase in number of cycle to failure with increasing Vickers hardness 


\section{Conclusions}

In order to obtain an indicator for the suppression of fatigue crack growth by peening, several peening techniques, including hybrid peening, were used to treat austenitic stainless steel SUS316L. Fatigue crack growth tests were done using a plate bending fatigue tester. The compressive residual stress generated at the surface and the residual stress depth profile were evaluated by X-ray diffraction. The Vickers hardness was also evaluated. The results obtained are summarized below:

1. Hybrid peening, which is a combination of different peening techniques, increases the number of cycles to failure, i.e., the resistance to fatigue crack growth, since it can introduce greater and deeper compressive residual stress compared to a single peening process; that is, it increases the area of integration under the compressive residual stress curve with respect to depth.

2. The number of cycles to failure depends strongly not only on the compressive residual stress at the surface but also the depth profile regardless of the peening technique. This increases linearly with the increasing area of integration under the compressive residual stress curve with respect to depth. Moreover the Vickers hardness also shows a close relationship with the number of cycles to failure. The favorable effect of the compressive residual stress introduced by peening on the suppression of the fatigue crack growth should be evaluated by not only the compressive residual stress at the surface but also its depth profiles since the fatigue crack grows both along the surface and in the depth with the semielliptical shape by the applied bending stress. The area of compressive residual stress obtained from the depth profile can be considered to be a resistance of metal treated by peening to the fatigue crack growth. These results indicate that improvements in the resistance to fatigue crack growth by peening can be estimated using that indicator.

\section{Acknowledgments}

This work was partly supported by the Japan Society for the Promotion of Science under the Grant-in-aid for Scientific Research (B) 24360040 and Young Scientists (Start-up) 24860004. Laser Peening was carried out at TOSHIBA Corporation, working cooperatively with Dr. Yuji Sano. The authors express their appreciation to both.

\section{References}

(1) Soyama, H., Sekine, Y. and Oyama, Y., Improvement of the Fatigue Strength of Stainless Steel SUS316L by a Cavitating Jet with an Associated Water Jet in Water, ISIJ International, Vol. 48 (2008), pp. 1577-1581.

(2) Soyama, H. and Sekine Y., Sustainable Surface Modification Using Cavitation Impact for Enhancement of Fatigue Strength Demonstrated by a Power Circulating Type Gear Tester, International Journal of Sustainable Engineering, Vol. 3 (2010), pp. 25-32.

(3) Nishikawa, M., Takakuwa, O. and Soyama, H., Evaluation of Yield Stress Distribution in the Surface Layer and Fatigue Properties of the Stainless Steel Modified by Cavitation Peening, Transactions of the JSME, Series A, Vol. 76 (2010), pp. 1367-1372.

(4) Sano, Y., Obata, M., Kubo, T., Mukai, N., Yoda, M., Masaki, K. and Ochi, Y., Retardation of Crack Initiation and Growth in Austenitic Stainless Steels by Laser Peening without Protective Coating, Materials Science and Engineering A, Vol. 417 (2006), pp. 334-340.

(5) Takakuwa, O., Nishikawa, M. and Soyama, H., Numerical Simulation of the Effects of Residual Stress on the Concentration of Hydrogen around a Crack Tip, Surface and Coatings Technology, Vol. 206 (2012), pp. 2892-2898.

(6) Takakuwa, O. and Soyama, H., Suppression of Hydrogen-Assisted Fatigue Crack Growth in Austenitic Stainless Steel by Cavitation Peening, International Journal of Hydrogen Energy, Vol. 37 (2012), pp. 5268-5276.

(7) Takakuwa, O. and Soyama, H., Using an Indentation Test to Evaluate the Effect of Cavitation Peening on the Invasion of the Surface of Austenitic Stainless Steel by 
Hydrogen, Surface and Coatings Technology, Vol. 206 (2012), pp. 3747-3750.

(8) Naito, A., Takakuwa, O. and Soyama, H., Development of Peening Technique Using Recirculating Shot Accelerated by Water Jet, Materials Science and Technology, Vol. 28 (2012), pp. 234-238.

(9) Soyama, H., Enhancing the Aggressive Intensity of a Cavitating Jet by Means of the Nozzle Outlet Geometry, Transactions of the ASME, Journal of Fluids Engineering, Vol. 133 (2011), pp. 101301-1-11.

(10) Soyama, H., Kikuchi, T., Nishikawa, M. and Takakuwa, O., Introduction of Compressive Residual Stress into Stainless Steel by Employing a Cavitating Jet in Air, Surface and Coatings Technology, Vol. 205 (2011), pp. 3167-3174.

(11) Sano, Y., Akita, K., Masaki, K., Ochi, Y., Altenberger, I. and Scholtes, B., Laser Peening without Coating as a Surface Enhancement Technology, Journal of Laser Micro Nanoengineering, Vol. 1 (2006), pp. 161-166.

(12) Kanou, S., Nishikawa, M. and Soyama, H., Effect of High Strain-Rate Deformation on Surface Mechanical Properties of Stainless Steel after Peening, Transactions of the JSME, Series A, Vol. 76 (2010), pp. 1775-1780.

(13) Kanou, S., Takakuwa, O., Mannava, S.R., Qian, D., Vasudevan, V.K. and Soyama, H., Effect of the Impact Energy of Various Peening Techniques on the Induced Plastic Deformation Region, Journal of Materials Processing Technology, Vol. 212 (2012), pp. 1998-2006.

(14) Matsui, K., Eto, H., Kawasaki, K., Misaka, Y. and Ando, K., Improvement in Fatigue Strength of Gears Hardened by Contour Induction Using Double Shot Peening, Transactions of the JSME, Series A, Vol. 65 (1999), pp. 1942-1947.

(15) Nishijima, S., Statistical Analysis of Fatigue Test Data, Journal of the Society of Materials Science, Japan, Vol. 29 (1980), pp. 24-29.

(16) Murakami, Y. and Endo, M., Effects of Hardness and Crack Geometry on $\Delta K_{\text {th }}$ of Small Cracks, Journal of the Society of Materials Science, Japan, Vol. 35 (1986), pp. 911-917.

(17) Takakuwa, O., Nishikawa, M. and Soyama, H., Estimation of the Depth of Surface Modification Layer Induced by Cavitation Peening, Journal of Materials Processing Technology, Vol. 212 (2012), pp. 1716-1722.

(18) Takakuwa, O. and Soyama, H., The Effect of Scanning Pitch of Nozzle for a Cavitating Jet during Overlapping Peening Treatment, Surface and Coatings Technology, Vol. 206 (2012), pp. 3747-3750.

(19) Takakuwa, O., Nishikawa, M. and Soyama, H., Suppression of Fatigue Crack Propagation in Steel by Cavitation Peening, Metal Finishing News, Vol. 11 (2010), pp. 58-60.

(20) Lads, D.A., Apelian, D. and Donald, J.K., Fracture Mechanics Analysis for Residual Stress and Crack Closure Corrections, International Journal of Fatigue, Vol. 29 (2007), pp. 687-694. 